UCRL-JC-126331

PREPRINT

\title{
RK-TBA Studies at the RTA Test Facility
}

\author{
S. Lidia, D. E. Anderson, S. Eylon,
}

E. Henestroza, T. Houck, L. Reginato,

D. Vanacek, G. Westenskow, and S. Yu

This paper was prepared for submittal to the Advanced Accelerator Concepts Conference

Lake Tahoe, CA

October 12-18, 1996

January 17, 1997

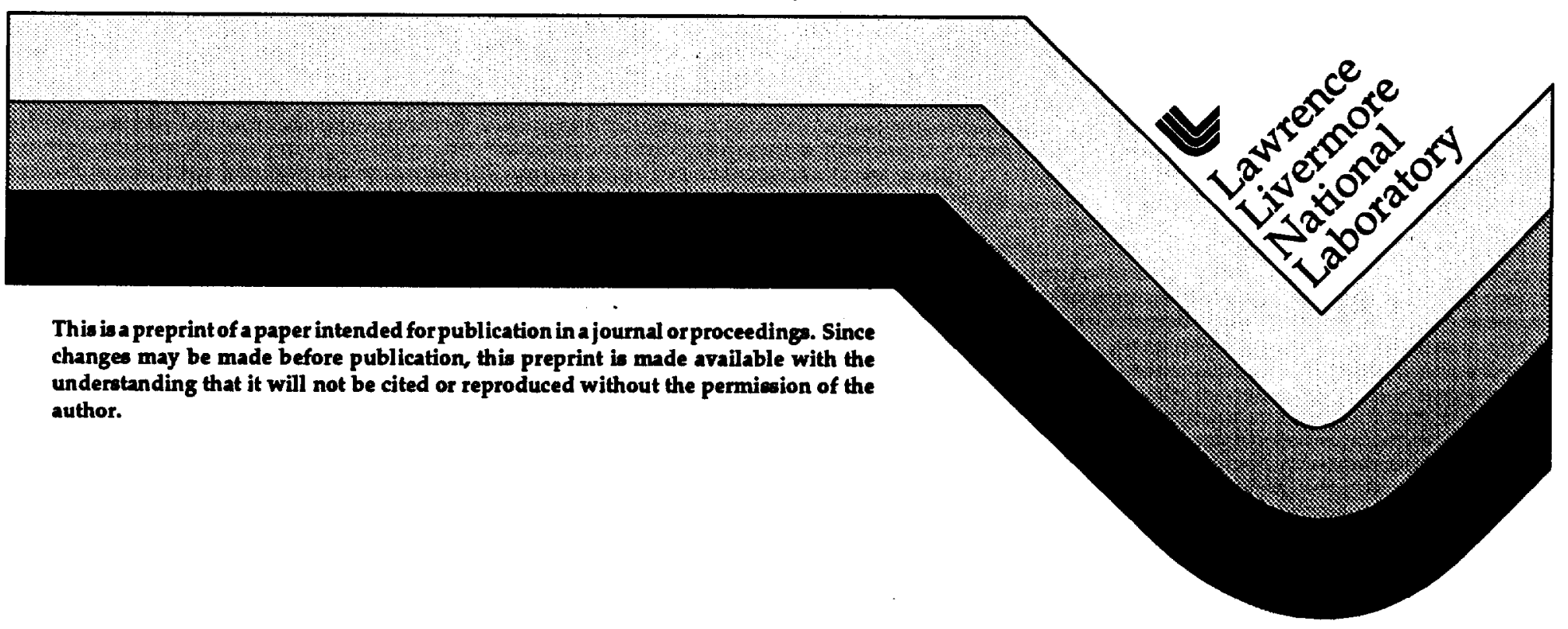




\section{DISCLAIMER}

This document was prepared as an account of work sponsored by an agency of the United States Government. Neither the United States Government nor the University of California nor any of their employees, makes any warranty, express or implied, or assumes any legal liability or responsibility for the accuracy, completeness, or usefulness of any information, apparatus, product, or process disclosed, or represents that its use would not infringe privately owned rights. Reference herein to any specific commercial product, process, or service by trade name, trademark, manufacturer, or otherwise, does not necessarily constitute or imply its endorsement, recommendation, or favoring by the United States Government or the University of California. The views and opinions of authors expressed herein do not necessarily state or reflect those of the United States Government or the University of California, and shall not be used for advertising or product endorsement purposes. 


\title{
RK-TBA Studies at the RTA Test Facility*
}

\author{
S. Lidia ${ }^{a}$, D. Andersona, S. Eylon ${ }^{a}$, E. Henestroza ${ }^{b}$, T. Houck ${ }^{c}$, \\ L. Reginato ${ }^{a}$, D. Vanecek ${ }^{a}$, G. Westenskowc, and S. Yua \\ a Lawrence Berkeley National Laboratory, I Cyclotron Road, Berkeley, CA 94720 USA, \\ bepartment of Applied Science, University of California, Davis, CA 95616 USA, \\ cLawrence Livermore National Laboratory, P.O. Box 808, Livermore, CA 94550 USA
}

\begin{abstract}
Construction of a prototype RF power source based on the RK-TBA concept, called the RTA, has commenced at the Lawrence Berkeley National Laboratory. This prototype will be used to study physics, engineering, and costing issues involved in the application of the RK-TBA concept to linear colliders. The status of the prototype is presented, specifically the 1-MV, 1.2-kA induction electron gun and the pulsed power system that are in assembly. The RTA program theoretical effort, in addition to supporting the development of the prototype, has been studying optimization parameters for the application of the RK-TBA concept to higher-energy linear colliders. An overview of this work is presented.
\end{abstract}

\section{INTRODUCTION}

A Lawrence Berkeley National Laboratory (LBNL) and Lawrence Livermore National Laboratory (LLNL) collaboration has been studying RF power sources based on the RK-TBA concept for several years [1, 2, 3]. The collaboration prepared a preliminary design study for a RF power source suitable for the NLC [4] last year. This RF power source, referred to as the TBNLC, is comprised of subunits, each approximately $340 \mathrm{~m}$ in length with 150 extraction structures generating $360 \mathrm{MW}$ per structure. The number of subunits is dependent on the power requirement for the collider, e.g. 76 subunits are required for a $1.5-\mathrm{TeV}$ collider. A test facility has been established at LBNL to verify the analysis used in the design study. The primary effort of the facility is the construction of a prototype TBNLC subunit that will permit the study of technical issues, system efficiencies, and costing.

Relativistic klystrons are not limited to X-band frequencies. We have formed a collaboration with the CERN Compact Linear Collider (CLIC) group to study a $30 \mathrm{GHz}$ RK power source for CLIC. We refer to this RF power source design as the RK-CLIC [5]. Many of the design features are shared between the TBNLC and RK-CLIC. More recently we have attempted to optimize the RK-TBA concept relative to the required IP physics of the collider instead of matching the RK's to existing collider designs.

\footnotetext{
"The work was performed under the auspices of the U.S. Deparment of Energy by LLNL under contract W-7405-ENG-48, LBNL under contract AC03-76SF00098, and FAR under SBIR Grant DE-FG03-95ER81974
} 
In the first section of this paper, we will discuss the development of the RTA. injector cathode and pulsed-power system, which has recently been constructed and is now undergoing testing. We will shift focus in the second section in order to discuss some recent work on extending the RK-TBA concept to higher energy and higher frequency colliders.

\section{RTA: PROTOTYPE RF POWER SOURCE}

Construction of the RTA, a prototype of the proposed TBNLC RF power source subunits [6], has started at LBNL. Details of the RTA design has been presented elsewhere $[7,8]$. Here, we describe the $1-\mathrm{MV}, 1.2-\mathrm{kA}$ induction electron gun and the pulsed power system for the gun.

\section{Induction Electron Gun}

An illustration of the 1-MV, 1.2-kA induction electron source, referred to as the gun, is shown in Figure 1. The cores are segmented radially to reduce the individual aspect $(\Delta r / \Delta z)$ ratios with each driven separately at about $14 \mathrm{kV}$. The lower aspect ratio reduces the variation in core impedance during the voltage pulse simplifying the pulse forming network (PFN) design. We chose a constant radius design for the cathode-side cells. This design increased the METGLAS ${ }^{\circledR}$ core volume by about $10 \%$, but the added cost was recovered in reduced insulator and fabrication costs. Figure 2 is a photograph of the completed cathode-half of the gun undergoing initial pulsed power tests. Currently, the cathode-half gun is being used to test various insulator configurations. The test results will be incorporated into the RTA's induction accelerator design.

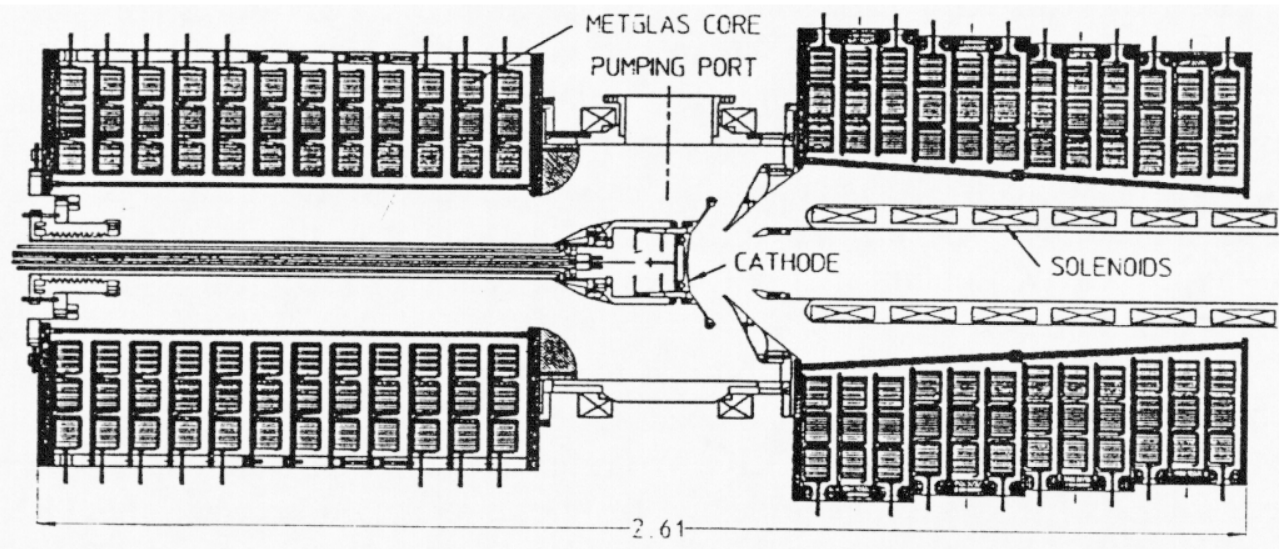

FIGURE 1. Illustration of the RTA gun, a 1.2-kA, 1-MeV induction electron source. 


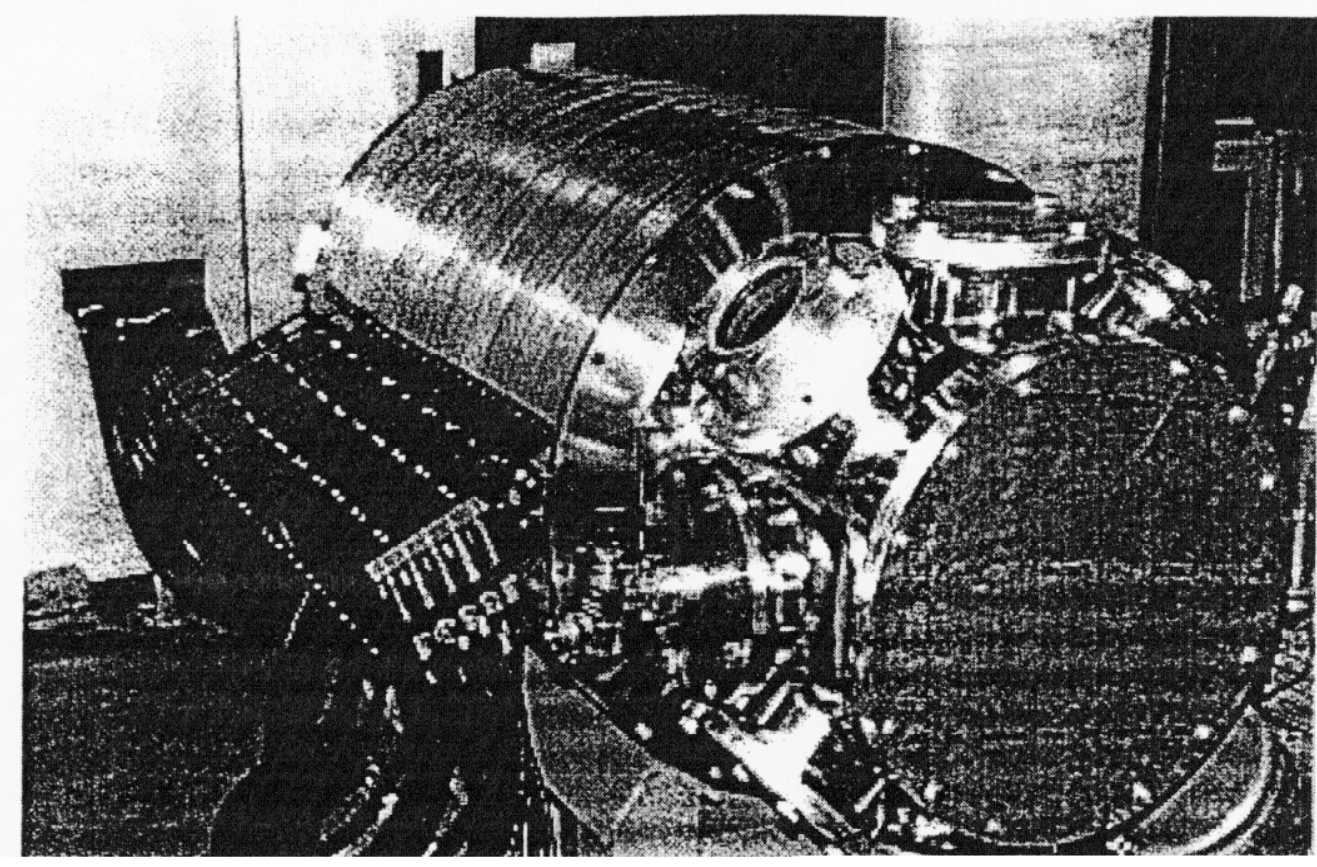

FIGURE 2. Photograph of the assembled cathode-half of gun. The cathode will be located within the pumping spool. Flange for the anode-half of gun is blanked off.

A novel feature of the gun design is the insulator. We are doing high voltage testing with a single, $30 \mathrm{~cm} \mathrm{ID,} \mathrm{PYREX}{ }^{\circledR}$ tube for the insulator with no intermediate electrodes. Average gradient along the insulator at the operating voltage of $500 \mathrm{kV}$ is about $5.1 \mathrm{kV} / \mathrm{cm}$. Maximum fields at the triple points, intersection of insulator, vacuum, and metal, is less than $3.5 \mathrm{kV} / \mathrm{cm}$. Maximum surface fields in the cathode half of the gun are about $85 \mathrm{kV} / \mathrm{cm}$. The rationale for using PYREX ${ }^{\circledR}$ is to explore methods of reducing the costs of induction injectors. PYREX ${ }^{\circledR}$ is significantly less expensive than ceramic, and additional savings are realized by avoiding intermediate electrodes. Since there is additional risk associated with this approach, our design allows for the addition of intermediate electrodes and/or substitution of a ceramic insulator with minimal impact to schedule or expense. However, the initial high-voltage tests on the cathode-side insulator are encouraging.

\section{Pulsed Power System}

The pulsed power system will consist of a 20-kV Energy Storage Bank Charging Power Supply, 3-kJ Energy Storage Bank, two Command Resonant Charging Chassis, 24 Switched Pulse Forming Networks, and four Induction Core Reset Pulsers. A photograph of one PFN is shown in Figure 3. Each PFN will drive a single 3-core induction cell. A sample pulse is shown in Figure 4. 


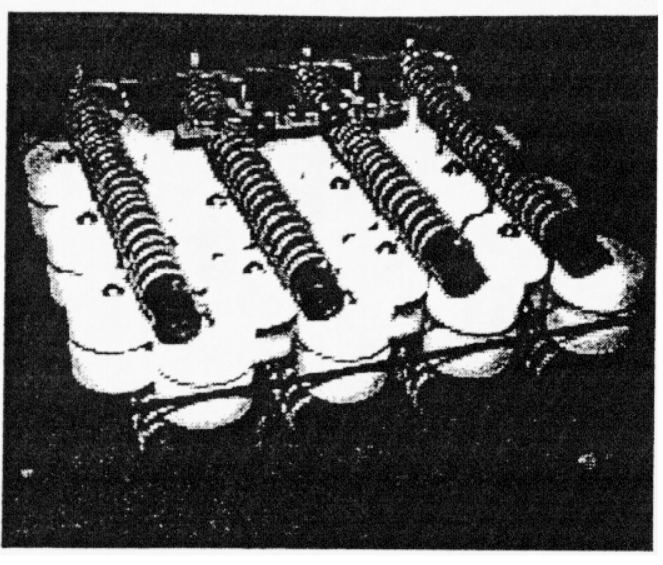

FIGURE 3. Photograph of single PFN used for driving a gun induction cell. The PFN is comprised of multiple LC stages charged to power pulse applied to induction cell. Top about $28 \mathrm{kV}$ and uses thyratron swithching is current (4 kAdiv) Time and middle trace

Segmenting the core in the induction cell and driving the individual core segments avoids a high-voltage step-up transformer. This reduces the developmental effort needed to achieve a "good" flattop pulse (minimal energy variation) and improves the efficiency of the overall pulsed power system. Our system of low-voltage PFNs driving multiple core induction cells is similar to the system envisioned for the extraction section in the TBNLC design. For the core material, we choose METGLAS $^{\circledR}$ alloy 2605 SC instead of the 2714AS, the preferred material for the TBNLC, due to the larger inner diameter gun cores. In the RTA gun configuration, the larger flux swing of $2605 \mathrm{SC}$ was of greater importance than the lower loss per unit volume of 2714AS. The RTA extraction section will use 2714AS to permit an accurate measurement of the pulsed power system efficiency expected for the TBNLC.

An area of concern is the consistency of the METGLAS ${ }^{\circledR}$ cores. Several core materials were tested at the RTA Test Facility [9] to establish a data base for design studies. However, this testing did not address the issue of consistency between cores of the same material. We now have a data base including the 38 cores of METGLAS ${ }^{\circledR}$ alloy 2605SC used in the construction of the cathode-half of the gun. Figure 5 shows the energy loss per unit volume for these cores at a flux swing rate, $\mathrm{dB} / \mathrm{dt}$, of $5 \mathrm{~T} / \mu \mathrm{s}$. The cores used $20 \mu \mathrm{m}$ thick $2605 \mathrm{SC}$ layers with mylar insulation and achieved an average packing fraction of $76 \%$, minimum of $72 \%$ and maximum of $78 \%$. The cores had a radial thickness of $5.8 \mathrm{~cm}$ with an inner radius of $19 \mathrm{~cm}, 27 \mathrm{~cm}$, or $35 \mathrm{~cm}$. The small, medium, and large cores in Figure 5 refer to the different inner radii. The three horizontal lines represent the average loss per volume for the respective core sizes. The smaller the core radius, the higher the loss per volume, as shown in the figure. However, total loss per core for the 38 cores was approximately the same with no significant dependence on core size. 


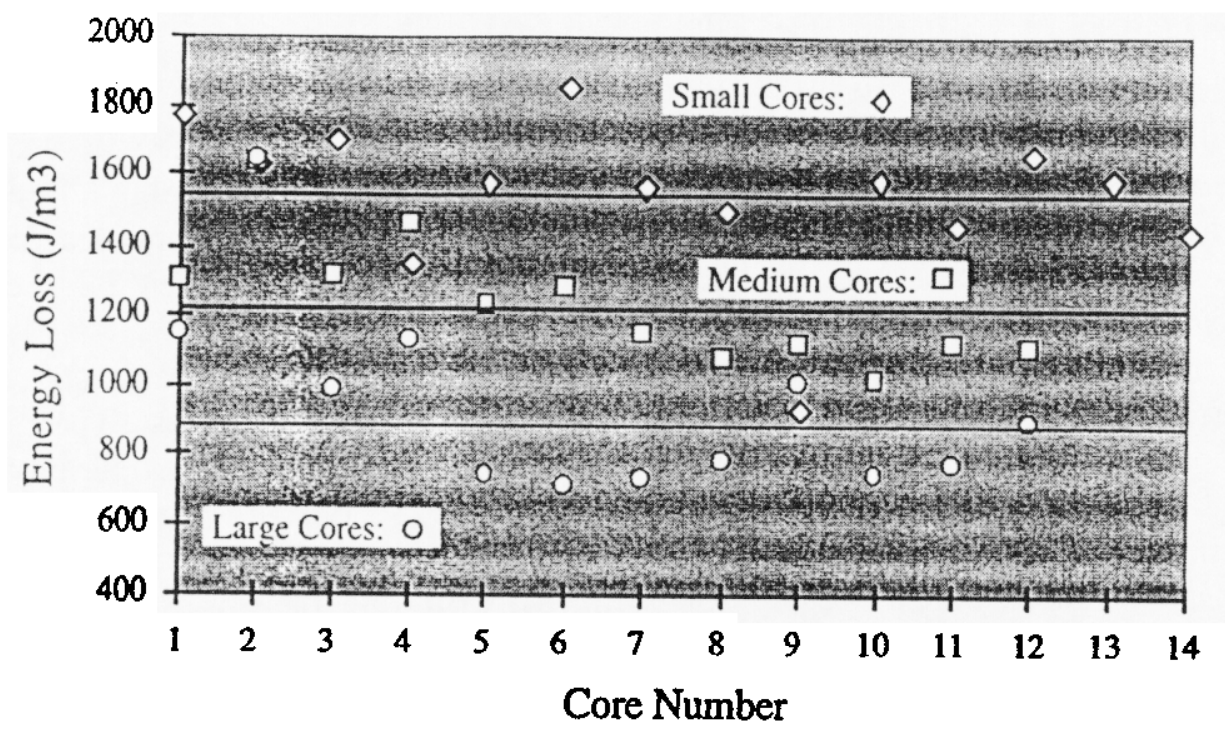

FIGURE 5. Test results for the METGLAS $\$$ alloy $2605 S C$ cores.

The standard deviation in loss per volume for the small and medium cores was $14 \%$ and the large core was $29 \%$. However, by matching the cores, the standard deviation for a three core cell was reduced to $4 \%$. If the core losses vary sufficiently, it becomes necessary to tailor individual PFNs to adjust for the different cell loads. For a large relativistic klystron, matching cell cores should permit acceptable loss variation.

\section{HIGHER-ENERGY, HIGHER-FREQUENCY COLLIDERS}

We are currently evaluating possible designs for a 5-TeV-scale collider [10], based on operating frequencies higher than $11.424 \mathrm{GHz}$. We propose the use of high current, high power beams in the main collider linacs, while loosening some of the stringent parameters in the final focus section. The accelerating structure in the main linacs must of necessity be heavily damped, as well as detuned to allow for fast roll-off of the short-range wakefields. This damped, detuned two-beam accelerator we dub the DD-TBA.

\section{Interaction Point Physics}

Requirements of high average luminosity, a usable level of beamstrahlung induced energy spread, and a low background of high energy photons lead to tradeoffs between beam power and beam quality. The definition of terms and a comprehensive review of the relevant IP physics in a linear collider can be found in Wilson's article [11], Palmer [12], and Irwin [13].

The NLC [14] klystron-based collider designs have exhibited overall wall plug to beam efficiencies around $10 \%$. In order to hold down total power 
consumption, a heavy burden is usually placed on generating and maintaining higher quality beams, keeping the beam power at lower levels. In this DD-TBA collider design, the net efficiency can be $50 \%$ or more. In this scheme, we choose instead to operate with much higher beam power in order to relax some of the constraints and challenges at the final focus. Various proposed schemes, and their IP parameter sets are listed in Table I. The parameters of the 1-TeV NLC case are included for comparison.

For the DD-TBA design we have allowed for both a larger beam spot size and normalized emittance, while keeping $\Upsilon$ and $\delta_{\mathrm{B}}$ at moderate values. The range of $\gamma$ considered in the various designs spans an order of magnitude. The physics of high $(\gg>1) \Upsilon$ interactions is still not understood, so placing any upper limit is somewhat premature. Also, the issue of energy resolution in the detector systems must be addressed before an upper limit on $\delta_{\mathrm{B}}$ can be imposed as a design constraint. However, in a reasonable 5-TeV collider design, it is very difficult to achieve an energy spread below $10 \%$.

Table 1. Comparison of linear collider IP parameters.

\begin{tabular}{|c|ccccc|}
\hline & Palmer [12] & Irwin [13] & Wilson [11] & DD-TBA $^{* *}$ & NLC \\
\hline$E_{\mathrm{cm}}(\mathrm{TeV})$ & 5.0 & 5.0 & 5.0 & 5.0 & 1.0 \\
$L_{\left(10^{35} \mathrm{~cm}^{-2} \mathrm{~s}^{-1}\right)}$ & 2.5 & 2.5 & 2.5 & 2.5 & 0.11 \\
$N\left(10^{10}\right)$ & 0.31 & 0.03 & 0.44 & 0.25 & 1.1 \\
$f_{\text {rop }} n_{b}(\mathrm{kHz})^{*}$ & 12.7 & 330 & 5.6 & 71 & 12.6 \\
$\sigma_{y}(\mathrm{~nm})$ & 0.2 & 0.1 & 0.1 & 0.4 & 5.1 \\
$R$ & 136 & $156^{*}$ & 700 & 180 & 49 \\
$\sigma_{\mathrm{Z}}(\mathrm{mm})$ & 20 & $27^{*}$ & 20 & 20 & 150 \\
$\varepsilon_{\mathrm{ny}}(\mathrm{nm})$ & 1.5 & 3.3 & 1 & 4 & 110 \\
$D_{y}$ & 7.3 & 7 & 7 & 2 & 7.6 \\
$H_{D}$ & 2 & $1.4^{*}$ & $1.1^{*}$ & 2 & 1.4 \\
$r$ & 21 & $4^{*}$ & 28 & 7.8 & 0.29 \\
$\delta_{B}(\%)$ & 27 & $10^{*}$ & 20 & 15.5 & 12.6 \\
$P_{\text {beam }}(\mathrm{MW})$ & 54 & 40 & 18 & 72 & 7.9 \\
\hline
\end{tabular}

" These parameters are not given explicitly by the authors, but have been derived from scaling relationships.

** We have used a value of $A_{y}$ equal to 0.10 .

\# $f_{\text {rep }}$ is the pulse train repetition frequency; $n_{b}$ is the number of bunches per train.

This loosening of beam quality does not come without its price. The RK power source is most efficient when generating long RF pulses (100's to 1000's of ns). Efficient use of that pulse means that we must use bunch trains that span it. To achieve the required luminosity, we must also pack the bunches tightly together. The current DD-TBA design uses trains of 4761 $0.4-\mathrm{nC}$ bunches with a separation of $2 \mathrm{RF}$ wavelengths. This gives a large DC current of $6.01 \mathrm{~A}$ during the pulse, which has a repetition rate of $10 \mathrm{~Hz}$. 


\section{High Gradient Structures}

The transport and acceleration of such large current beams necessitates a hard study of the high gradient structures. The introduction by Wilson [15] provides an in-depth discussion of the pertinent physics. Once an average current is chosen, the structure design becomes a tradeoff between accelerating gradient and RF to beam power conversion efficiency. We adopt an approach that uses heavy beam loading to boost efficiency, while maintaining relatively high loaded accelerating gradients. The linac structures are designed to have high efficiency in transfer of RF power to beam power $(-80 \%)$, with high input RF power $(400$ MW/structure). The structure parameters are listed in Table 2.

The transverse wakefields in this structure are quite severe due to the large current. By using heavily damped structures we can produce designs with low dipole mode Q's. This can significantly damp wakefield levels generated by a bunch at a given point in the structure by the time the next bunch arrives.

Table 2. Linac structure parameters.

\begin{tabular}{|c|c|c|c|}
\hline $\begin{array}{c}\text { Frequency } \\
\text { Bgroup } \\
a / \lambda \\
r / Q \\
Q \\
\text { Fill time } \\
\tau\end{array}$ & $\begin{array}{c}30 \mathrm{GHz} \\
0.10 \\
0.214 \\
23.7 \mathrm{k} \Omega / \mathrm{m} \\
4425 \\
14 \mathrm{~ns} \\
0.298\end{array}$ & $\begin{array}{c}\text { Idc } \\
\text { Input power } \\
\text { Peak gradient } \\
\text { Average gradient } \\
\text { Power into beam } \\
\text { Power into walls } \\
\text { Structures per m }\end{array}$ & $\begin{array}{c}6.01 \mathrm{~A} \\
400 \mathrm{MW} \\
244 \mathrm{MV} / \mathrm{m} \\
126 \mathrm{MV} / \mathrm{m} \\
316 \mathrm{MW} \\
80 \mathrm{MW} \\
2\end{array}$ \\
\hline
\end{tabular}

\section{Relativistic Klystron Source}

The relativistic klystron power source design is similar to the proposed TBNLC. For this design, each unit would power 600 high gradient structures, so that each linac arm would require 79 DD-TBA units.

Each DD-TBA consists of a $3.5-\mathrm{kA}, 5.0-\mathrm{MeV}$ injector, a beam modulation unit, an adiabatic capture section to bunch and accelerate the beam, the main RF extraction section, and an afterburner section to extract power from the beam while decelerating it prior to the dump. At the entrance to the main extraction section, the beam has an average energy of $25 \mathrm{MeV}$ and carries $3150 \mathrm{~A}$ of RF current with $1750 \mathrm{~A}$ of $\mathrm{DC}$ current. Each relativistic klystron has 300 extraction sections to power 600 high gradient structures. The ultimate efficiency of the relativistic klystron is limited by the number of extraction sections the beam can pass through before succumbing to beam breakup (BBU) instabilities. Careful attention must then be paid to transport and stability.

\section{Transport and Beam Stability}

Permanent magnet quadrupoles are employed to provide a magnetic FODO lattice. The lattice has a $0.33 \mathrm{~m}$ period with a $60^{\circ}$ phase advance per period, 
giving a $2 \mathrm{~m}$ betatron period. The quadrupole magnets are ferrites with an $800 \mathrm{G}$ poletip field, $1.0 \mathrm{~cm}$ bore radius, and 0.48 occupancy factor. For a normalized edge emittance of $2000 \pi \mathrm{mm}$-mrad, the equilibrium beam edge radius will be about $2.0 \mathrm{~mm}$.

Two severe transverse instabilities have been identified in the RK-TBA. One is a low frequency mode associated with the induction modules, and the other is a high frequency mode due to the RF extraction structures. Similar instabilities will exist in this design, but at higher frequencies. Simple scaling arguments [16] imply that the high frequency instability growth rate in this design could be a factor of 4 higher than in the TBNLC design, while the low frequency instability rate could be 10 times higher, if left uncorrected.

Beam energy spread should result in effective Landau damping to counter the low frequency instability. Transport of the beam depends upon the ferrite permanent magnet quadrupoles. Increasing the poletip field of the magnets will also increase the quadrupole gradient. Alternatively, we can increase the bore of the beam pipe as well as induction gaps, while increasing the poletip field at fixed beam energy, and maintain the same betatron period. Thus, we can decrease the transverse impedance due to the induction gaps, and hence the low frequency instability growth rate.

The higher frequency mode is more severe. Our solution is to place the extraction structures at half-betatron wavelengths, on the nodes. The growth rate should be similarly depressed as in the betatron node scheme for the TBNLC [3]. Field error tolerances in the quadrupoles become an issue, since this instability is sensitive to the details of the focusing lattice with respect to the positions of the RF output structures.

Another beam dynamic issue related to the induction cell is the extraction of $\mathrm{RF}$ power from the modulated beam. Power is absorbed by various materials in the cell and reduces efficiency. Techniques for lowering the longitudinal impedance of the cell at $30 \mathrm{GHz}$, therefore minimizing power loss in the output structures, is an active area of study.

The idler cavities in the adiabatic capture section and the extraction structures in the main section are detuned from synchronism at $30 \mathrm{GHz}$. This compensates for bunch lengthening effects, and provides longitudinal focusing. The synchrotron oscillation, induced by the power extraction and reacceleration, has a period of $91 \mathrm{~m}$.

\section{Induction Modules}

We have designed a system to provide $155 \mathrm{kV}$ per induction cell, to replace the beam energy lost in the RF output structures. For our long pulse ( $300 \mathrm{~ns}$ ), and assuming that we drive the core to saturation, the 2714AS material has the lowest losses, and hence the largest efficiency. For a DC current of $1750 \mathrm{~A}$ and voltage of $155 \mathrm{kV} /$ cell, the net core efficiency is $\sim 91 \%$. 


\section{Travelling Wave Output Structures}

We obtain a zero-order design for the $30-\mathrm{GHz}$ output structures by scaling the physical dimensions from our $11.424 \mathrm{GHz}$ design. The structure is initially designed to operate in the $2 \pi / 3$ mode, but is then detuned by $30^{\circ}$ so that it will actually resonate in the $\pi / 2$ mode when driven at $30 \mathrm{GHz}$. The structure parameters are listed in Table 3.

Table 3. Travelling wave output structure parameters.

\begin{tabular}{|cc|cc|}
\hline Frequency & $30 \mathrm{GHz}$ & $\mathrm{R} / \mathrm{Q}$ & $19 \mathrm{~W} / \mathrm{cell}$ \\
Mode & $2 \pi / 3^{*}$ & Pout & $801 \mathrm{MW}$ \\
$\beta$ group & 0.65 & Max. field & $344 \mathrm{MV} / \mathrm{m}$ \\
$\mathrm{a} / \lambda$ & 0.62 & & \\
\hline
\end{tabular}

* Detuned by $30^{\circ}$ - resonant travelling mode is $\pi / 2$.

\section{System Efficiencies}

The pulse power system suitable for this design would utilize a DC power supply, a Command Resonant Charging (CRC) chassis, and thyratron switching, like the earlier TBNLC proposal. We can make predictions of the efficiency of the pulse power system based on our previous work. These estimates are listed below in Table 4. Here the drive beam fall time has been included to account for losses at the end of the voltage pulse that are dissipated in the induction cores. Drive beam to RF losses account for the beam losses at the front end of the relativistic klystron, and for beam power lost at the dump. Auxiliary power accounts for cooling and vacuum systems, etc. We include the RF to beam efficiency of the high gradient structures, and calculate the net efficiency of the RK-TBA to be $-52 \%$.

Table 4. Power source efficiencies.

\begin{tabular}{|cc|cc|}
\hline DC Power & 0.93 & Drive Beam Fall Time & 0.94 \\
Command Resonant Charging & 0.96 & Drive Beam to RF & 0.93 \\
Modulator (thyratron) & 0.94 & Auxiliary Power & 0.98 \\
Induction Cells & 0.91 & RF to High Energy Beam & 0.79 \\
\hline Net Wall Plug to Beam & & 0.52 \\
\hline
\end{tabular}

\section{Future Collider and Power Source Studies}

We are exploring techniques to modulate beams and extract power at much higher frequencies $(30 \mathrm{GHz}-120 \mathrm{GHz}$ or higher). At these frequencies, free electron lasers become good candidates for modulating beams [17]. We are currently designing inductively detuned RF extraction cavities at $30-35 \mathrm{GHz}$, to take advantage of some available beam sources. W-band $(90-120 \mathrm{GHz})$ systems are also being considered in support of high-gradient structure research occurring elsewhere. 


\section{ACKNOWLEDGMENTS}

We thank Andy Sessler and Swapan Chattopadhyay for their support and guidance. Yu-Jiuan Chen and George Caporaso provided valuable assistance with the induction accelerator design. Ming Xie provided helpful advice with our initial collider modelling. Wayne Greenway and Bob Candelario we thank for their excellent technical support.

\section{REFERENCES}

1. Sessler, A.M. and Yu, S.S., "Relativistic Klystron Two-Beam Accelerator," Phy's. Rev. Lett. 54, 889 (1987).

2. Westenskow, G.A., and Houck, T.L., "Relativistic Klystron Two-Beam Accelerator," IEEE Trans. on Plasma Sci., 22, 750 (1994).

3. Giordano, G., et al., "Beam Dynamic Issues in an Extended Relativistic Klystron," in Proc. of the 1995 IEEE Particle Accelerator Conf., 1995, pp. 740-742.

4. Loew, G.A., and Weiland, T., International Linear Collider Technical Review Committee Report 1995, Stanford, Stanford University, 1995, pp. 61-65, 83, 84.

5. Houck, T.L., et al., "Scaling the TBNLC Collider to Higher Frequencies," in Proceedings of XVIII Intermational Linac Conference (LINAC96), 1996.

6. Houck, T.L., and Westenskow, G.A., "Prototype Microwave Source for a Relativistic Klystron Two-Beam Accelerator" IEEE Trans. on Plasma Sci., 24, 938 (1996).

7. Houck, T., et al., "RK-TBA Prototype RF Source, in Proceedings of 3rd ICFA Workshop on Pulsed RF Sources for Linear Colliders (RF96), 1996.

8. Westenskow, G.A., et al., "Relativistic Klystron Two-Beam Accelerator Studies at the RTA Test Facility," in Proceedings of XVIII International Linac Conference (LINAC96), 1996.

9. Reginato, L., et al., "Engineering Conceptual Design of the Relativistic Klystron Two-Beam Accelerator Based Power Source for 1-TeV Next Linear Collider," in Proc. of the 1995 IEEE Particle Accelerator Conf., 1995, pp. 743-745.

10. Lidia, S.M., et. al., "Relativistic Klystron Two-Beam Accelerator Approach to Multi-TeV e $e^{+} e^{-}$ Linear Colliders," contributed to the APS New Directions for High Energy Physics Workshop, Snowmass, CO, USA, July 1996.

11. Gaponov-Grekhov, A.V., and Granatstein, V.L., eds., Applications of High Power Microwaves, Boston: Artech House, 1994, ch. 7.

12. Palmer, R.B., Ann. Rev. Nucl. Sci. 40, 529-92 (1990).

13. Irwin, J., "Bird's IP View of Limits of Conventional e+e- Linear Collider Technology," presented at the 6th Workshop on Advanced Accelerator Concepts, Lake Geneva, Wisconsin, June 12-18, 1994.

14. The NLC Design Group, Zeroth-Order Design Report for the Next Linear Collider, SLAC Report 474, Stanford University, Stanford, CA, May 1996.

15. Wilson, P., SLAC-PUB-2884 (rev.) (1991).

16. Chao, A.W., Physics of Collective Instabilities in High Energy Accelerators, New York: John Wiley \& Sons, 1993.

17. Gardelle, J., et. al., "Analysis of the beam bunching produced by a free electron laser," submitted for publication in Physics of Plasmas, June 1996. 


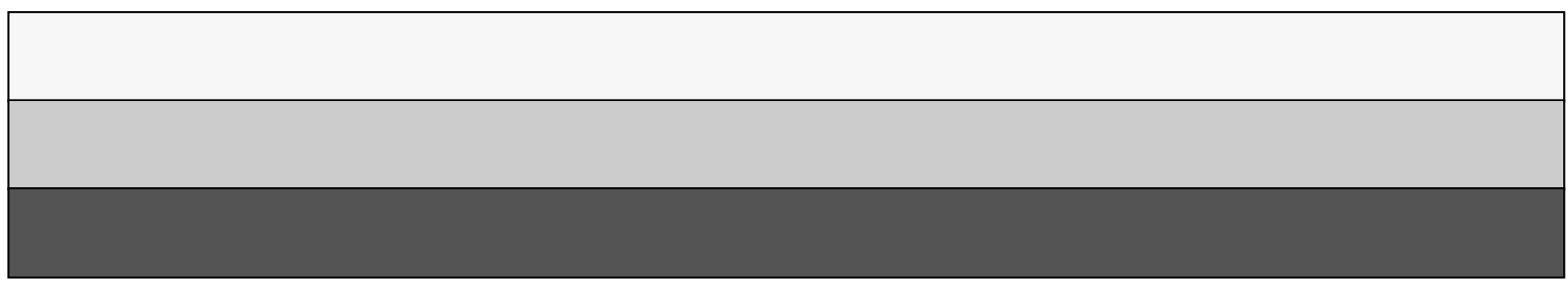

